Brickman et al point out that "concepts like 'reasonable' and 'practicable' sum up British regulatory philosophy, a philosophy generally shared by industry". Discussions about what these terms mean as far as particular chemicals are concerned are carried out in private between civil servants and industry. In the case of decisions taken by Britain's Health and Safety Executive, workers' trades unions are also involved. The result, say the authors, is usually a compromise that all sides are prepared to live with.

On the question of whether there is a 'safe' concentration for carcinogens to which workers can be exposed without risk, Britain seems to be out of step. British regulators, are favourably disposed to the concept of a threshold. As pointed out in the book, a guidance note issued by the British Health and Safety Executive in 1978 , proposed a method of determining a "practical threshold of neoplastic response" while conceding that a "precisely defined" threshold cannot be attained. But Britain, it seems, is the only country that has banned some chemicals in the workplace because of their carcinogenic properties.

In Germany, the analysis of hazards is usually carried out by scientific advisory committees within each Ministry, who then also support appropriate regulations. It appears that these committees have a similar philosophy to the US Agencies in that they accept that there is no safe

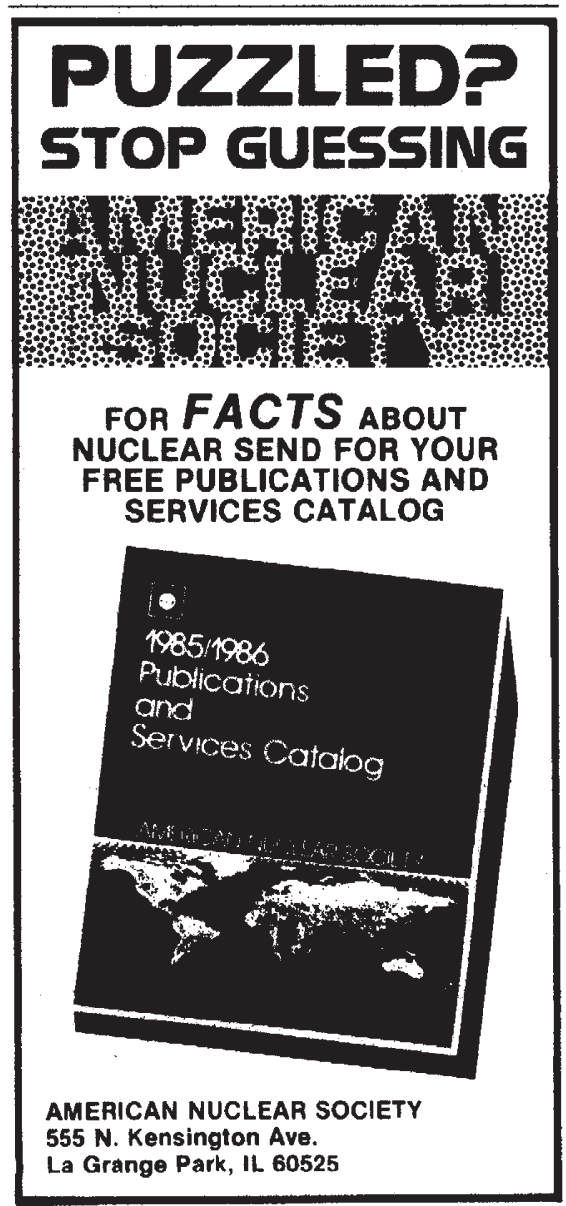

Reader Service No.58 threshold level for carcinogens. Because the German Commission on hazardous substances in the workplace argues that there is no way of assessing a threshold and calculating a tolerance level, this leaves the Federal Labour Ministry free to set exposure standards for carcinogens at any level it regards as economically and technically feasible. Similarly, the French are reluctant to establish threshold limiting values, and the strategy for regulating carcinogens is to "combine strict medical monitoring with reporting and personal hygiene requirements".

In the United States, however, legislation is preferred. But the strict standards for chemicals in the workplace recommended initially by Regulatory Agencies are invariably toned down by a process of attrition in the courts. The end result of this is standards similar to those in force in Europe.

\section{Get together}

\section{Marie Boas Hall}

Science Reorganized: Scientific Societies in the Eighteenth Century. By James E. McClellan III. Columbia University Press: 1985. Pp.413. \$38.50, £41.80.

To join with others in a more or less formal group seems a natural human instinct of modern society. European scholars have long done so, in forms conditioned by the state of society: in the Renaissance under noble or princely patrons, later as a subsidiary of centralized monarchies, later still as a manifestation and a reflection of emergent nation-states. The first resultant academies were mainly literary or musical or scholarly; as science developed in the seventeenth century its practitioners drew together, either by correspondence or by association, and scientific academies, institutes and societies were born. And it is the societies and organizations themselves that form the focus of $\mathrm{Dr}$ McClellan's book.

Of these emergent academies the Royal Society of London (founded 1660, chartered 1662) and the Académie Royale des Sciences of Paris (1666) are the oldest in continuous existence, although not the first to be conceived. Both differed from earlier foundations in being independent of a private patron, in being incorporated entities and in publicizing the work of their members. The Académie (itself parallel to the Académie Française of 1635) was the prototype of modern national institutes and academies, its members paid by and sometimes appointed by the state, while the Royal Society was and is independent of the Government, though adviser to it and an agent of it.

Until roughly 1730 the Royal Society had the more eminent members and hence the greater reputation; slowly, in the wake
While the author's principal conclusion is the need in the United States for a more uniform approach to rule-making, and an opportunity for more negotiations between competing interests, they do not envisage less information on chemical hazards being released to the public (something which would win widespread approval in Europe). It is ironic that at the same time that some Americans are recognizing the benefits of toning down their procedures, many Europeans are starting to see merit in a system of greater accountability - that is, they would like more people to be let into the kitchen. This well-researched and well-argued book will be an excellent starting point for people of both persuasions.

Alastair Hay is a lecturer in the Department of Chemical Pathology, University of Leeds, Old Medical School, Thoresby Place, Leeds LS2 9JT, UK

of reform in 1699, the Académie reversed the situation. Because of this and the fact that French culture and politics dominated eighteenth-century life in continental Europe, later academies were imitations of that of France, until Berlin, St Petersburg (both initially mainly consisting of foreign savants), Uppsala, Turin and a host of provincial cities all possessed formal organizations with charters, publications and paid members. These were sometimes purely scientific, sometimes, especially later in the century with growing linguistic nationalism, combining a scientific with a parallel literary section, while England, after the growth of private provincial societies, about 1790 saw the rise of the "Lit. and Phil." movement.

What was the cause of all this activity? Dr McClellan as he surveys the eighteenth-century scientific academy sees it as the result of increasing professionalism in science (he does not discuss nonscientific groupings). He is interested in the organizations, which he describes and analyzes fully, not in the individuals who made them up nor, except where cooperation between societies was involved, in the work they accomplished. This gives a lack of solidity to his account, reinforced by a certain naivety about European (including English) history, pointed up by the American sections. (Nor has he a very sharp grasp of language.) $\mathrm{He}$ is at his best in describing the structure of the new continental European academies and the relationships between them and he rightly regards as innovative the beginning of a formal (as distinct from a personal) exchange of publications begun in midcentury. There is a very great deal of information in this book which clearly shows how scientific academies developed during the eighteenth century.

Marie Boas Hall, 14 Ball Lane, Tackley, Oxford OX5 $3 A G$ is Emeritus Reader in History of Science and Technology of the University of London. 